\title{
Monitoring and Analysis of Single Tube Temperature Distribution in Heat Exchanger Simulator Using TPA 81 Thermopile Array
}

\author{
Murry Raditya ${ }^{1}$, Gunawan Nugroho², Abdurrahman Rahyang Tutuko², Halen Dinata Atmaja ${ }^{1}$
}

\begin{abstract}
The Energy and Environmental Engineering Laboratory had a heat exchanger simulator which was used to determine the temperature changes with respect to time due to air velocity. This simulator used tubes which were used to find out the temperature change with time. The working principle of this simulator was to monitor changes in temperature on the tube that had been preheated and then cooled using a fan contained in the simulator. This study performed temperature measurements using a TPA81 thermal array sensor. We chose this sensor because it could measure the temperature without touching the object and had 8 pixels for image measurement. This was because the process of reducing the temperature of the tube becomes purely caused by the fan and not from the outside environment. The results obtained from this study were visualization of temperature distribution using the Thermal Array TPA81 sensor, having a linearity value of $0.034 \%$, a precision value of the instrument of $98.1 \%$, an accuracy value of $0.285 \%$, and error value of $0.154\left(\mathrm{~W} / \mathrm{m}^{2} \mathrm{~K}\right)$. For the analysis of temperature distribution, it was concluded that the value of the temperature did not affect the value $h$, because the value of $h$ (the coefficient of heat transfer convection) is distributed with time.
\end{abstract}

Keywords - Simulator Heat Exchanger (HE), Tubes, Thermal array sensor

\section{INTRODUCTION}

The Energy and Environmental Conservation engineering laboratory has a heat exchanger simulator which is used to determine the temperature changes with respect to time due to air velocity. This simulator has tubes which were used to find out the temperature change with time. The working principle of this simulator is to monitor changes in temperature on the tubes that has been preheated and then cooled using a fan that was already in the simulator. During this time, the way to monitor temperature is to manually use a conventional temperature meter and need to be in contact with tubes (thermocouple, RTD, etc.). This causes the temperature reduction process was not purely caused by the fan, but also the outside environment because of the way of how to insert the sensor by piercing the simulator.

Therefore in this research, we proposed a monitoring system which was expected able to monitor and analyze the temperature distribution of the arrangement of tubes without pierce thriugh the simulator and also able to obtained temperature distribution which will be analyzed using temperature changes over time. This system uses a thermopile array temperature sensor that used an infrared array of $8 \times 1$ so that the measurement did not interfere with the performance of the heat exchanger simulator.

TPA81 shown in Figure 1, could detect infrared light with a wavelength between 2 um-22um ( 1 micro meter $=$ millionth of a meter). These wavelengths were produced

\footnotetext{
${ }^{1}$ Departement of Instrumentation Engineering, Institut Teknologi Sepuluh Nopember, Surabaya, 60111, Indonesia

${ }^{2}$ Departement of Engineering Physics, Institut Teknologi Sepuluh Nopember, Surabaya, 60111, Indonesia
}

by hot objects and only heat radiation detected by the sensor, TPA 81 could measure temperature without having to touch a heat source. As an illustration, TPA81 can detect the temperature of a candle flame within a distance of 2 meters without being affected by room light.
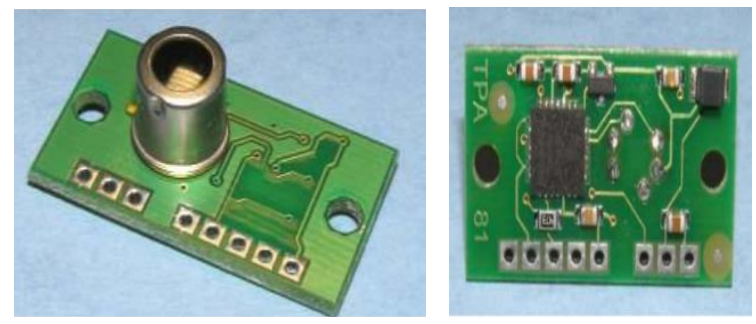

Figure 1. TPA81 Thermopile Array

One of the most important parts of a heat exchanger was the hot contact surface. On this surface heat transfer occurred from one substance to another as it was shown in Figure 2. The wider the total contact area of the heat exchanger made the value of the heat transfer efficiency higher. Under certain conditions, there was one additional component that could be used to increase the total area of this heat transfer contact area. The component was the Telemetering fins.
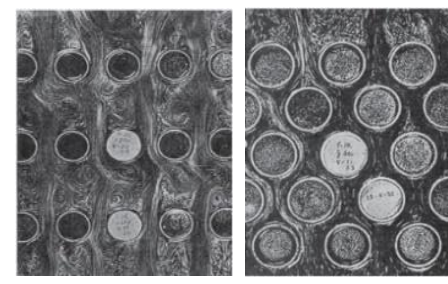

Figure 2. Flow patterns for staggered and in-line types 
The arrangement of the tube as shown in Figure 3 in the tube bank was characterized by:

1. ST transverse pitch

2. SL longitudinal pitch,

3. Diagonal pitch (diagonal pitch) of SD, between the center of the tube determined by the equation (1)

$S_{D}=\sqrt{S_{L}^{2}+\left(\frac{S_{T h}}{2}\right)^{2}}$
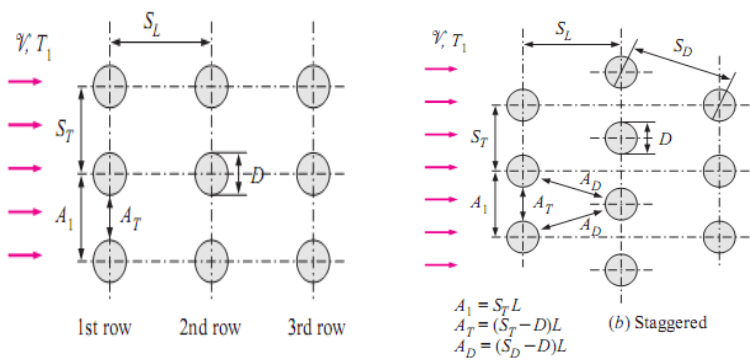

(a) In-line

Figure 3. Patterns of pipeline arrangement in in-line tubes and staggered tube banks

When a fluid enters the tube bank, the flow area will decrease from A1 $=$ STL to an area of AT $=(S T-D) L$, so the flow velocity will increase. Therefore, Reynold's number was defined based on the maximum speed that was by the equation (2)

$R e_{D}=\frac{\rho \cdot V \max . D}{\mu}=\frac{V \max . D}{v}$

For in-line arrays, the maximum velocity occurs in the area of flow between tubes, mass conservation can be formulated by the following equation:

$\rho V A_{1}=\rho V_{\max } A_{T}$

or

$V S_{T}=2 V_{\max }\left(S_{T}-D\right)$

So that the maximum speed for the arrangement In-Line:

$$
V_{\max }=\frac{S_{T}}{S_{T}-D} \mathrm{~V}
$$

Staggered

$$
\begin{aligned}
& \text { if } S_{D}<\frac{\left(S_{T}+D\right)}{2} \text { then } V_{\max }=\frac{S_{T}}{2\left(S_{T}-D\right)} \mathrm{V} \\
& \text { if } S_{D}>\frac{\left(S_{T}+D\right)}{2} \text { then } V_{\max }=\frac{S_{T}}{S_{T}-D} \mathrm{~V}
\end{aligned}
$$

The average value of the Nusselt number for the flow regarding the zukauskas tube banks form a correlation that has a general equation:

$$
N u_{D}=\frac{h \cdot D}{k}=C \cdot R e_{D}^{m} \cdot \operatorname{Pr}^{n}\left(\frac{P r}{P r_{S}}\right)^{0.25}
$$

Where the value of $C, m$, and $n$ constant, depending on the size of Reynold. The correlation can be found in Table 1 for $0.7<\operatorname{Pr}<500$ and $0<\operatorname{ReD}<2.10^{6}$

\begin{tabular}{|c|c|c|}
\hline Arrangement & Range of $\operatorname{Re}_{\mathrm{D}}$ & $\begin{array}{c}\text { Correlation } \\
\end{array}$ \\
\hline & $0-100$ & $\mathrm{Nu}_{\mathrm{D}}=0.9 \mathrm{Re}_{\mathrm{D}}^{0.4} \mathrm{Pr}^{0.36}\left(\mathrm{Pr}_{\mathrm{Pr}} / \mathrm{Pr}_{\mathrm{s}}\right)^{0.25}$ \\
\hline . & $100-1000$ & $\mathrm{Nu}_{\mathrm{D}}=0.52 \mathrm{Re}_{\mathrm{D}}^{0.5} \mathrm{Pr}^{0.36}\left(\mathrm{Pr} / \mathrm{Pr}_{\mathrm{s}}\right)^{0.25}$ \\
\hline 当 & $1000-2 \times 10^{5}$ & $\mathrm{Nu}_{\mathrm{D}}=0.27 \operatorname{ReD}^{0.63} \mathrm{Pr}^{0.36}\left(\mathrm{Pr}_{\mathrm{Pr}} / \mathrm{Pr}_{\mathrm{s}}\right)^{0.25}$ \\
\hline & $2 \times 10^{5}-2 \times 10^{6}$ & $\mathrm{Nu}_{\mathrm{D}}=0.033 \mathrm{Re}^{0.8} \mathrm{Pr}^{0.5}\left(\mathrm{Pr}_{\mathrm{r}} / \mathrm{Pr}_{\mathrm{r}}\right)^{0.25}$ \\
\hline$\tau^{2}$ & $0-500$ & $\mathrm{Nu}_{\mathrm{D}}=1.04 \mathrm{ReD}^{0.8} \mathrm{Pr}^{0.36}\left(\mathrm{Pr} / \mathrm{Pr}_{\mathrm{s}}\right)^{0.25}$ \\
\hline$\vec{\nu}$ & $500-1000$ & $\mathrm{NuD}_{\mathrm{D}}=0.71 \mathrm{Red}^{0.5} \mathrm{Pr}^{0.36}\left(\mathrm{Pr}_{\mathrm{Pr}} / \mathrm{Pr}\right)^{0.25}$ \\
\hline 步 & $1000-2 \times 10^{5}$ & $\mathrm{Nu}_{\mathrm{D}}=0.35\left(\mathrm{~S}_{\mathrm{T}} / \mathrm{S}_{\mathrm{L}}\right)^{0.2} \operatorname{Re}_{\mathrm{D}}^{0.6} \mathrm{Pr}^{0.36}\left(\mathrm{Pr} / \mathrm{Pr}_{\mathrm{s}}\right)^{0.25}$ \\
\hline$\frac{\pi}{2}$ & $2 \times 10^{5}-2 \times 10^{6}$ & $\mathrm{Nu}_{\mathrm{D}}=0.031\left(\mathrm{~S}_{\mathrm{T}} / \mathrm{S}_{\mathrm{L}}\right)^{0.2} \operatorname{Re}_{\mathrm{D}}{ }^{0.8} \mathrm{Pr}^{0.36}\left(\mathrm{Pr}_{\mathrm{Tr}} / \mathrm{Pr}_{\mathrm{s}}\right)^{0.25}$ \\
\hline
\end{tabular}

TABLE 1.

NUSSELT NUMBER CORRELATION FOR CROSS FLOW OVER TUBE BANK FOR $\mathrm{N}>16$ and $0.7<\operatorname{Pr}<500$

The average Nusselt number in Table 1 above was used on tube banks with 16 or more rows. If the number of NL series was below 16, then the equation above could be used corrected by the use of $F$ factors

$$
N u_{D, N_{L}}=F N u_{D}
$$

Where the $\mathrm{F}$ factor was a correction factor whose value can be taken from Table 2.4. > 1000, the correction factor did not depend on the Reynold number value.

TABLE 2.

CORRECTION FACTOR F TO BE USED $N u_{D, N_{L}}=F N u_{D}$ for NL $<16$ and $\mathrm{ReD}>1000$

\begin{tabular}{ccccccccc}
\hline \hline $\mathrm{N}_{\mathrm{L}}$ & 1 & 2 & 3 & 4 & 5 & 7 & 10 & 13 \\
\hline In-Line & 0.70 & 0.80 & 0.86 & 0.90 & 0.93 & 0.96 & 0.98 & 0.99 \\
Staggered & 0.64 & 0.76 & 0.84 & 0.89 & 0.93 & 0.96 & 0.98 & 0.99 \\
\hline
\end{tabular}

This research focused in finding the thermal coefficient through contactless measurement which was very helpful to isolate the environmental noise that could occurred because of the contacted sensor and measurement object.

\section{METHODOLOGY}

This research was carried out based on systematic steps as shown in the flow chart Figure 4.
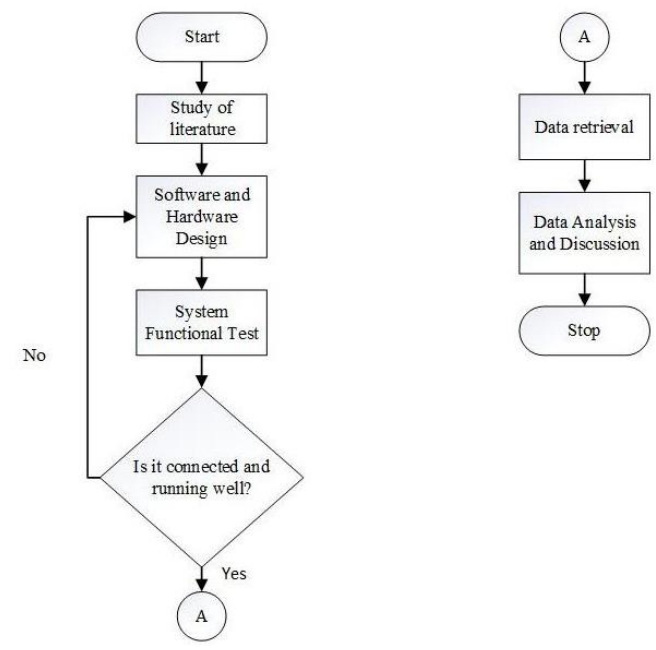

Figure 4. Flowchart and methodology

In the hardware and software designer in this study there were several stages, namely the manufacture of a series of thermal array sensors (TPA81), then go into making a microcontroller program for processing data on the sensor 
that will bring up the $\mathrm{h}$ value (convection heat transfer coefficient) and the measured temperature value. In the design of this temperature monitoring system there was a block diagram. Figure 5 below showed the system's block diagram for this research.

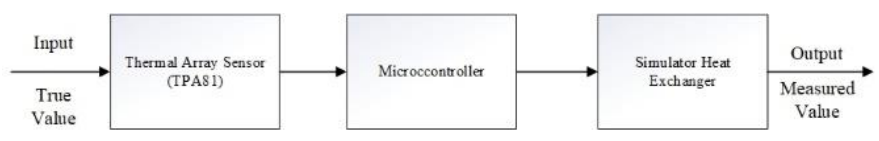

Figure 5. System Block Diagram

The block diagram explained the system flow. Starting from the input (measured temperature), Thermal Array Sensor (Sensor), Microcontroller (signal conditioning and processing element), Heat Exchanger (Plant) Simulator.

The hardware design was carried out to design prototypes of the plant to suit real conditions, as well as design systems that will later work as sensors, controls, actuators, or supporting components of the system or plant.

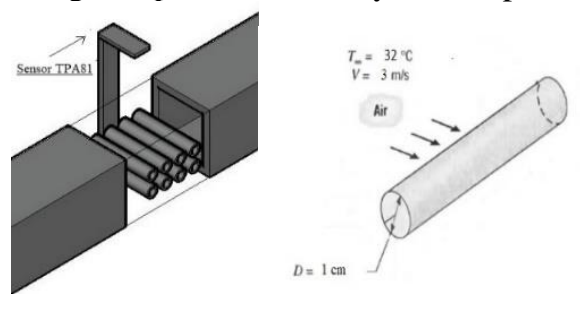

Figure 6. The design of the system

In this design the sensor used to measure temperature was a thermal array sensor (TPA81), then the tube used has a diameter of $1 \mathrm{~cm}$ or $0.01 \mathrm{~m}$, and the tube would be cooled using a fan with a flow velocity of $3 \mathrm{~m} / \mathrm{s}$ within a temperature around the tube at $32^{\circ} \mathrm{C}$.

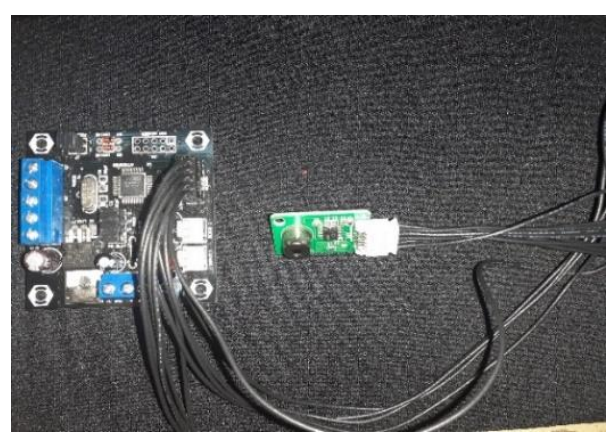

Figure 7. TPA 81 Module Series

After designing and manufacturing hardware, it was necessary to design software that consists of several stages. The first stage was the software design of the controller program so that the sensor readings could read or sense, then calculated the value of $\mathrm{h}$, and displayed it on the monitor. The following flowchart was an explanation of the program used.

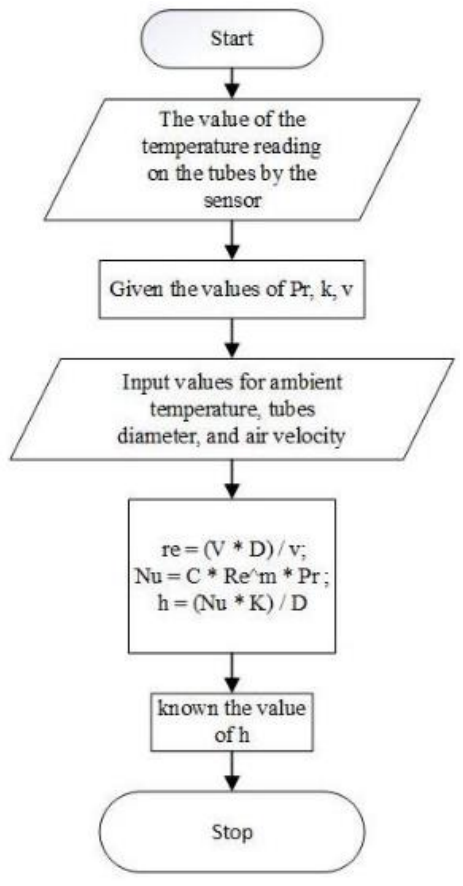

Figure 8. Flowchart for program

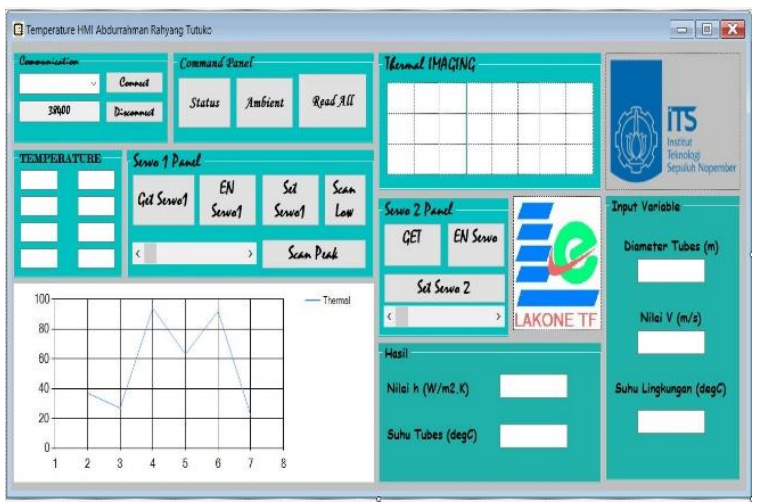

Figure 9. HMI temperature interface design

\section{RESULTS AND DISCUSSION}

\section{A. Sensor Static Characteristics}

TPA81 sensor testing was carried out in a temperature range of $30^{\circ} \mathrm{C}-90^{\circ} \mathrm{C}$ with water media. For each increment, 5 times the sensor readings were taken. The standard tool used for comparison was a standard thermometer. The following data was obtained from testing the tool. 
TABLE 3.

TPA81 TEST DATA

\begin{tabular}{|c|c|c|c|c|}
\hline \multirow{2}{*}{$\begin{array}{l}\text { Stand ard } \\
\text { Reading }\end{array}$} & \multicolumn{2}{|c|}{ Average Reading } & \multirow{2}{*}{$\begin{array}{l}\text { Average } \\
\text { Reading }\end{array}$} & \multirow{2}{*}{ Correction } \\
\hline & $\mathbf{U}_{\mathbf{p}}$ & Down & & \\
\hline 30 & 30.8 & 31 & 30.9 & -0.9 \\
\hline 35 & 35.8 & 35.4 & 35.6 & -0.6 \\
\hline 40 & 41 & 41 & 41 & -1 \\
\hline 45 & 45.4 & 45.4 & 45.4 & -0.4 \\
\hline 50 & 50.8 & 51 & 50.9 & -0.9 \\
\hline 55 & 54.8 & 55.8 & 55.3 & -0.3 \\
\hline 60 & 60.8 & 60.8 & 60.8 & -0.8 \\
\hline 65 & 65.2 & 65.4 & 65.3 & -0.3 \\
\hline 70 & 70.8 & 70.8 & 70.8 & -0.8 \\
\hline 75 & 75.6 & 75.4 & 75.5 & -0.5 \\
\hline 80 & 80.4 & 80.2 & 80.3 & -0.3 \\
\hline 85 & 85.4 & 85.8 & 85.6 & -0.6 \\
\hline 90 & 90.4 & 90.6 & 90.5 & -0.5 \\
\hline \multicolumn{3}{|c|}{ Total } & 787.9 & -7.9 \\
\hline \multicolumn{3}{|c|}{ Average } & 60.60769 & -0.60769 \\
\hline
\end{tabular}

From Table 3, it produced a comparison chart of the TPA81 sensor readings with the following standards:

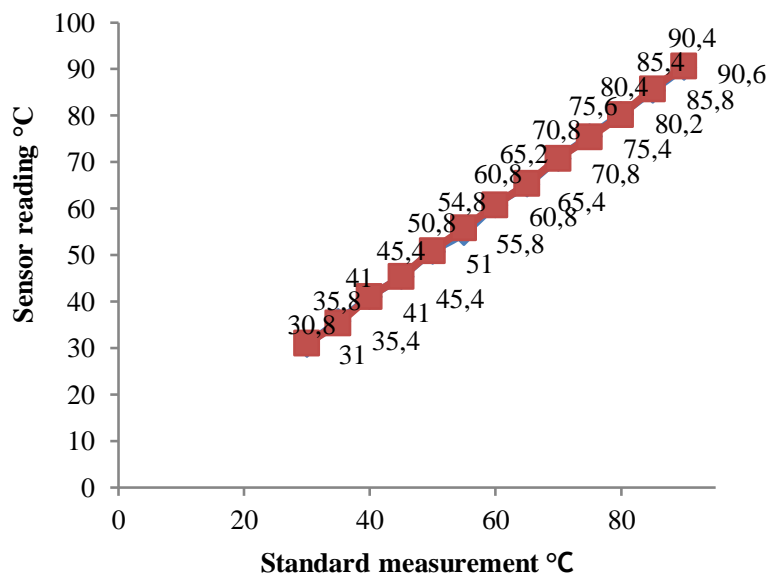

$\longrightarrow$ Up Reading $\quad=$ Down Reading

Figure 10. Linearity Graph

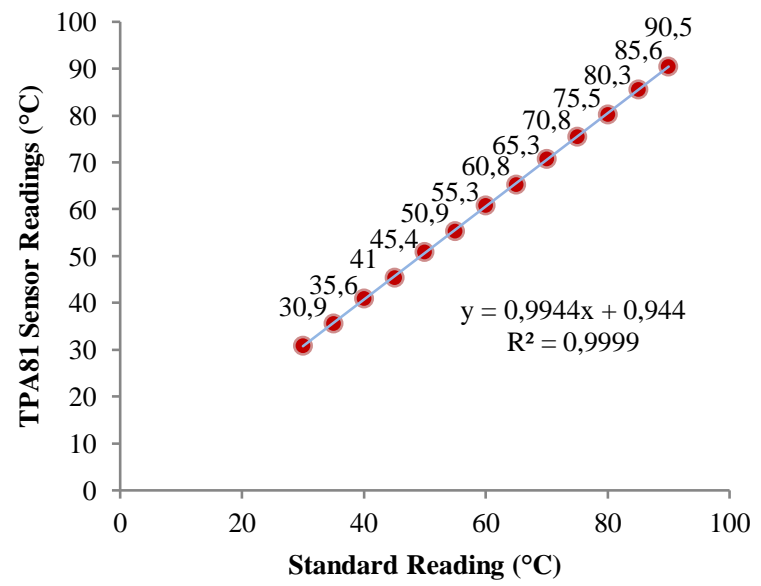

- Sensor Reading —_Linear (Sensor Reading)

Figure 11. Comparison graph of TPA81 with Standard sensors

From Figure 10 above, it was shown that the reading of the instrument was approaching the standard measurement.
However, there were a number of points where there were still errors. Here were the results of the calculation of the TPA81 sensor's static characteristic values:

Sensitivity $=\frac{\Delta O}{\Delta I}=\frac{90.6-31}{90-30}=0,993$

Linearity

$\widehat{N}=\frac{[O-K I+a] \max }{0 \max -0 \min } 100 \%$

Where:

$\mathrm{K}$ (sensitivity) $=0,993$

$a($ zero bias $)=\mathrm{O}_{\min }-\mathrm{KI}_{\min }$

$a=31-(0,993)(30)$

$a=1,21$

So that the linearity of $0.034 \%$ was obtained. In this linear function the line shows a slight difference between the actual or actual reading and the ideal straight line.

Precision

$P=1-\left|\frac{Y n-X n}{Y n}\right| x 100 \%$

With $Y n$ is standard reading, $X n$ is tool reading

$P=1-|0,019| x 100 \%=98,1 \%$

\section{B. TPA81 sensor validation}

In this research, sensor validation was done by comparing the calculation of the value of $h$ calculated using a tool designed and manual calculations. So that the results obtained as in Table 4.

TABLE 4. COMPARISON FOR CALCULATING H-COEFFICIENT

\begin{tabular}{cccccc}
\hline \hline No & $\begin{array}{c}\text { Measured } \\
\text { Temperature } \\
\left({ }^{\circ} \mathbf{C}\right)\end{array}$ & Time & $\begin{array}{c}\text { The Value of } \mathbf{h}\left(\mathbf{W} / \mathbf{m}^{2} \cdot \mathbf{K}\right) \\
\text { Tool } \\
\text { Calculation }\end{array}$ & $\begin{array}{c}\mathbf{M} \text { a n u a } \\
\text { Calculation }\end{array}$ & Error \\
\hline 1 & 220 & 0 & 53.71 & 54.13 & 0.42 \\
2 & 163 & 60 & 53.71 & 53.87 & 0.16 \\
3 & 95 & 120 & 53.73 & 54.23 & 0.5 \\
4 & 72 & 180 & 53.7 & 54.21 & 0.51 \\
5 & 57 & 240 & 53.7 & 53.68 & -0.02 \\
6 & 48 & 300 & 53.71 & 53.71 & 0 \\
7 & 43 & 360 & 53.72 & 53.72 & 0 \\
8 & 39 & 420 & 53.74 & 53.74 & 0 \\
9 & 37 & 480 & 53.74 & 53.73 & -0.01 \\
10 & 36 & 540 & 53.75 & 53.73 & -0.02 \\
& Mean & & 53.721 & 53.875 & 0.154 \\
\hline \hline
\end{tabular}

So, based on the data in Table 4 the accuracy of the calculation was $0.285 \%$ and the calculation error made by the tool was $0.154\left(\mathrm{~W} / \mathrm{m}^{2} \mathrm{~K}\right)$, so the calculation done by the tool was quite in accordance with the Analysis of Temperature Distribution in Tubes theory.

The sensor test was read out for 10 minutes with a 60 second time sampling. TPA 81 sensor reading data along with the results of the calculation of the value of $h$ can be seen in Table 4 and with equation (13) we obtained the data calculation for the value of $\mathrm{q}$ can be seen in Table 5 .

$$
q=h \Delta T
$$


TABLE 5 .

CALCULATION OF Q VALUES

\begin{tabular}{ccccc}
\hline \hline No & $\begin{array}{c}\text { Measured } \\
\text { Temperature } \\
\left({ }^{\circ} \mathbf{C}\right)\end{array}$ & Time & $\begin{array}{c}\text { The Value of h } \\
\left(\mathbf{W} / \mathbf{m}^{2} \cdot \mathbf{K}\right)\end{array}$ & $\begin{array}{c}\text { The Value of } \mathbf{q} / \mathbf{A} \\
\left(\mathbf{W} / \mathbf{m}^{2}\right)\end{array}$ \\
\hline 1 & 220 & 0 & 53.71 & 10097.48 \\
2 & 163 & 60 & 53.71 & 7036.01 \\
3 & 95 & 120 & 53.73 & 3384.99 \\
4 & 72 & 180 & 53.7 & 2148 \\
5 & 57 & 240 & 53.7 & 1342.5 \\
6 & 48 & 300 & 53.71 & 859.36 \\
7 & 43 & 360 & 53.72 & 590.92 \\
8 & 39 & 420 & 53.74 & 376.18 \\
9 & 37 & 480 & 53.74 & 268.7 \\
10 & 36 & 540 & 53.75 & 215 \\
\hline \hline
\end{tabular}

Figure 12 below was a graph of the sensor readings along with the results of the calculation of the value of $h$ at each point and a graph of the value of $q$ at each known point value of h, in Figure 12 and Figure 13.

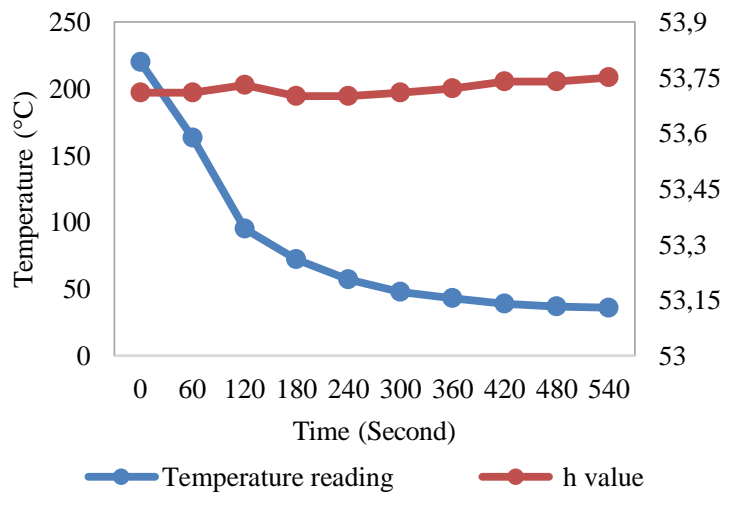

Figure 12. Graph of TPA81 sensor reading

Based on Figure 12 above, the sensor was tested when the tube was cooling. Temperature monitoring measurement was carried out to determine the temperature of a single-tube, then calculation the value of $h$ (convection heat transfer coefficient) was conducted, it was seen from Figure 12, the value of the temperature did not affect the magnitude or smallness of the $h$ value (convection heat transfer coefficient). So, the calculations carried out by the tool in accordance with existing theories.

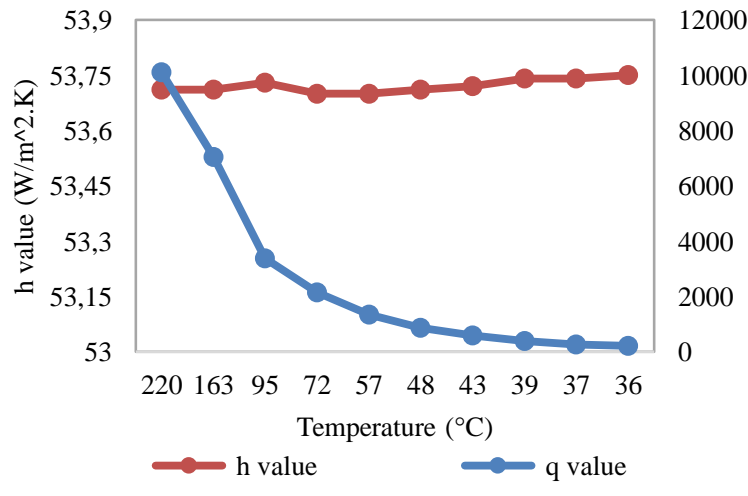

Figure 13. Graph of q/A values
Based on Figure 13 above the temperature monitoring system was also carried out to find out the value of $\mathrm{q}$ produced when it has gotten the $h$ value at each temperature point. it can be concluded that the higher the temperature the greater the value of the heat transfer rate, even though the magnitude or smallness of the value of $h$ at each temperature point is different.

\section{CONCLUSION}

Based on the results of testing, measuring, and analyzing temperature distribution on the arrangement of tubes in the heat exchanger simulator plant, it could be concluded that:

a. Visualization of temperature distribution or temperature monitoring system has been made using Thermal Array TPA81 sensor, where the TPA81 sensnor has a linearity value of $0.034 \%$, then a precision value based on comparison of sensor readings with the standard of $98.1 \%$ has been obtained, then the accuracy and error values from the calculation of $h$ value by tools with the existing theory that is equal to $0.285 \%$ and $0.154 \mathrm{~W} / \mathrm{m}^{2} . \mathrm{K}$.

b. Analysis of temperature distribution in one tube shows that the temperature value does not affect the size and size of the $h$ value (convection heat transfer coefficient), because the $h$ value (convection heat transfer coefficient) is distributed with time.

\section{REFERENCES}

[1] F. P. Incropera, D. P. Dewitt, T. L. Bergman and A. S. Lavine, Fundamentals of Heat and Mass Transfer Seventh Edition, Canada: John Wiley and Sons, 2011.

[2] Bergles, A.E. (1999).Enhanced heat transfer:Endles frontier, or mature and routine? J.Enhnced Heat Transfer.

[3] Hendawan Soebhakti,'Thermal Array TPA81 Application"10 Febuari 2009

[4] Kusuma, George Endri. Perpindahan Panas untuk Politeknik. Surabaya : Politeknik Perkapalan Negeri Surabaya.

[5] J. L. Honorato, I. Spiniak and M. Torres-Torriti, "Human Detection Using Thermopiles," 2008 IEEE Latin American Robotic Symposium, Natal, Rio Grande do Norte, 2008, pp. 151-157, doi: 10.1109/LARS.2008.21.

[6] A. Bengnarly dan H. Wicaksono, "Pengaplikaisan TP. dan CMPS03 pada Rancang Bangun Robot Beroda KR 2013," Jurnal Ilmiah Mahasiswa Universitas Surabaya, 2, no. 2, pp. 1-16, 2013.

[7] I. Permana, T. A. Ajiwiguna dan M. R. Kirom, "Compar of heat transfer coefficient on single tube and," dalam International Conference on Physics and Its Applicat (ICOPIA), 2019.

[8] S. Parnin dan M. M. Rahman, "Human location estima using thermopile array sensor," dalam 6th Internatic Conference on Mechatronics - ICOM'17, 2017.

[9] D. Samuel dan B. Sugumaran, "Fault Detection Transmission Line Using Thermopile Array and Real t IR Bitmap Generation," International Journal 
Engineering Development and Research, vol. 2, no. 2, 1462-1465, 2014.

[10] S. Mohamed-Nabil and S. Ossama, "Generalization of the heat transfer coefficient concept," 2008 Second International Conference on Thermal Issues in Emerging Technologies, Cairo, 2008, pp. 159-166, doi: 10.1109/THETA.2008.5188777. 